J. Lake Sci. (湖泊科学), 2013, 25(1): 47-54

http: //www. jlakes. org. E-mail : jlakes@niglas.ac.cn

(C) 2013 by Journal of Lake Sciences

\title{
高密度蓝藻厌氧分解过程与污染物释放实验研究
}

\author{
尚丽霞 ${ }^{1,2}$, 柯 凡 $^{1,2}$, 李文朝 ${ }^{1}$, 徐宪根 ${ }^{1,2}$, 宋媛媛 ${ }^{1,2}$, 冯慕华 ${ }^{1 * *}$ \\ (1: 中国科学院南京地理与湖泊研究所湖泊与环境国家重点实验室,南京 210008) \\ (2:中国科学院大学,北京 100049)
}

摘 要: 采用批次培养实验模拟高密度蓝藻堆积发生的厌氧分解过程, 分析蓝藻的分解速率及污染物释放规律. 厌氧分 解实验中, 设置三组蓝藻初始密度分别为 $2.23 \times 10^{12} 、 1.19 \times 10^{13} 、 4.47 \times 10^{13} \mathrm{cells} / \mathrm{L}$, 得到叶绿素 $\mathrm{a}$ 的分解速率常数分别 为 $0.074 、 0.133 、 0.081 \mathrm{~d}^{-1}$. 蓝藻厌氧分解过程中水体呈酸性, 电导率呈上升趋势, 最高值为 $949 \mu \mathrm{S} / \mathrm{cm}$. 化学需氧量持续 升高, 而 $\mathrm{UV}_{254}$ 值先升高后降低, 说明水体中有机物浓度增大, 并逐渐由大分子分解为小分子有机物. 蓝藻厌氧分解释放 出大量溶解态氮、磷, 溶解态有机氮逐渐被降解为无机氮, 铵态氮含量占 $90 \%$ 以上. 研究表明, 高密度蓝藻堆积发生厌氧 分解可释放大量有机物和溶解态营养盐至水体中, 并且随着蓝藻密度升高, 污染物释放强度增大. 因此水华期间应及时 打捞蓝藻, 以避免蓝藻大量堆积死亡导致水源区水质下降并影响自来水出水质量.

关键词: 蓝藻; 厌氧分解; 污染物释放

\section{Laboratory research on the contaminants release during the anaerobic decomposition of high-density cyanobacteria}

\author{
SHANG Lixia ${ }^{1,2}$, KE Fan ${ }^{1,2}$, LI Wenchao ${ }^{1}$, XU Xiangen ${ }^{1,2}$, SONG Yuanyuan ${ }^{1,2}$ \& FENG Muhua ${ }^{1}$ \\ (1: State Key Laboratory of Lake Science and Environment, Nanjing Institute of Geography and Limnology, Chinese Academy \\ of Sciences, Nanjing 210008, P. R. China) \\ (2: University of Chinese Academy of Sciences, Beijing 100049, P. R. China)
}

\begin{abstract}
The anaerobic decomposition of high-density cyanobacteria and the kinetics of contaminants release were investigated based on a set of batch tests in this study. The results showed that the degradation rates of chlorophyll-a ( Chl. a were 0. 074, 0.133 , and $0.081 \mathrm{~d}^{-1}$, respectively, at different cyanobacterial densities of $2.23 \times 10^{12}, 1.19 \times 10^{13}$ and $4.47 \times 10^{13}$ cells $/ \mathrm{L}$, respectively. The chemical oxygen demand increased while the $\mathrm{UV}_{254}$ value increased initially and then decreased, suggesting that the release of organic compounds increased, but the molecules of which were reduced gradually during the degraded process. Accordingly, the $\mathrm{pH}$ of incubation solution remained acidic and the conductance increased, up to $949 \mu \mathrm{S} / \mathrm{cm}$. The decomposition of cyanobacteria resulted in a high release of nitrogen and phosphorus. Moreover, dissolved organic nitrogen was degraded gradually into inorganic nitrogen form, in which the amount of ammonia nitrogen accounts for $90 \%$. The results demonstrate that the anaerobic decomposition of high-density cyanobacteria can release a large amount of organic compounds and nutrients into water, furthermore the release of contaminants increases with the increasing density of cyanobacteria. Therefore, to avoid high-density cyanobacteria deteriorating water quality and even threatening drinking water safety, we need to remove cyanobacteria timely when algal bloom occurs in the lake which is served as water resource.
\end{abstract}

Keywords: Cyanobacteria; anaerobic decomposition; contaminants release

受人类活动的影响,我国部分湖泊富营养化严重, 蓝藻水华频繁发生 ${ }^{[14]}$. 在一定的气象条件下,蓝藻局 部堆积厚度可达数厘米甚至数十厘米 ${ }^{[5]}$, 大量消耗水体中的溶解氧. 蓝藻在厌氧条件下腐烂分解. 大量蓝藻

* 国家水体污染控制与治理科技重大专项项目(2012ZX07103-005-001) 和国家自然科学基金项目(41171366)联合资助. 2012-03-16 收稿;2012-06-18 收修改稿. 尚丽霞,女, 1986 年生,博士研究生;E-mail : shanglx2008@ yahoo. cn.

** 通信作者;E-mail:mhfeng@ niglas. ac. cn. 
堆积衰亡不但导致沉积物中磷的内源释放量增大 ${ }^{[6]}$, 而且可能引发 “黑水团” 现象使水体散发出恶臭 ${ }^{[7-8]}$, 影 响水体的感官性状. 如果水华在水源地取水口附近大量集聚则可能引起水源地的水质恶化,危及供水 安全 ${ }^{[9-10]}$.

蓝藻堆积死亡形成大量有机碎屑, 分解时可释放大量营养盐和有机物, 一部分沉积到底泥中, 另一部分 会停留在水体中为更多藻类的生长提供营养条件. 陈伟民等 ${ }^{[11]}$ 的研究表明, 微囊藻好氧降解过程释放的溶 解态总磷占水体总磷的 $53 \%$. 蓝藻碎屑分解速率 $\left(0.072 \sim 0.271 \mathrm{~d}^{-1}\right)$ 很快, 氮、磷营养盐迅速释放, 并且磷的 释放速率高于氮 ${ }^{[12]}$. 堆积密度可影响蓝藻衰亡时营养盐释放过程, 随堆积密度增大, 营养盐释放浓度增 加 ${ }^{[13]}$. 可见, 蓝藻死亡分解会显著改变水体中营养盐和有机物的含量, 影响湖泊水质. 巢湖是我国第五大淡 水湖, 东部水源区是重要的饮用水源地. 近 30 年来, 由于流域内产业经济和人口快速增长, 巢湖水质严重恶 化, 生态系统功能退化, 富营养化问题十分突出. 本课题组监测发现, 在一定的气象条件下, 蓝藻大量暴发时 堆积厚度可达数厘米, 表层水体蓝藻密度高达 $10^{13} \mathrm{cells} / \mathrm{L}$, 并在戻氧条件下死亡分解. 以往文献多针对低密 度下蓝藻的死亡分解或未控制厌氧条件进行研究, 对高密度蓝藻堆积情况下厌氧分解过程的研究鲜有报 道. 因此开展高密度蓝藻腐烂分解对水体影响的研究具有重要意义. 由于蓝藻大量堆积在湖湾内, 不易受到 风或水流的影响, 浓厚的蓝藻堆积甚至可以抑制水流和风浪; 且蓝藻堆积一定厚度时系统内部受到氧的扩 散影响极小, 故试验环境选择在碘量瓶中, 旨在模拟研究过度堆积形成的厌氧环境下的蓝藻降解过程对水 体的影响. 选择 3 种不同堆积密度蓝藻 $\left(2.23 \times 10^{12} 、 1.19 \times 10^{13}\right.$ 和 $\left.4.47 \times 10^{13} \mathrm{cells} / \mathrm{L}\right)$ 进行厌氧分解过程研 究, 分析污染物释放强度, 旨在揭示蓝藻堆积一死亡一腐烂过程对饮用水源的污染效应, 为及时清除堆积蓝 藻、防止水源污染提供科学依据.

\section{1 材料与方法}

\section{1 样品采集与试验设计}

2010 年 10 月于巢湖东半湖水源区 $\left(31^{\circ} 35^{\prime} 31^{\prime \prime} \mathrm{N}, 117^{\circ} 50^{\prime} 47^{\prime \prime} \mathrm{E}\right)$ 用孔径为 $64 \mu \mathrm{m}$ 的浮游植物网收集漂浮 于水体表层的水华蓝藻, 常温下用去离子水清洗数遍后配制成 3 组不同密度的藻液. 蓝藻密度由低到高为 $2.23 \times 10^{12} 、 1.19 \times 10^{13}$ 和 $4.47 \times 10^{13} \mathrm{cells} / \mathrm{L}$, 分别用 $\mathrm{D}_{\mathrm{L}} 、 \mathrm{D}_{\mathrm{M}}$ 和 $\mathrm{D}_{\mathrm{H}}$ 表示. 藻液中不另外添加营养元素, 测定的 污染物均由蓝藻分解产生. 藻液经混合均匀后平行分装人 $250 \mathrm{ml}$ 碘量瓶中, 每个密度梯度重复 18 次. 水封 使其与空气隔绝, 模拟蓝藻局部堆积形成的厌氧条件. 将装有藻液的碘量瓶置于恒温振荡器, 在 $25 \pm 1^{\circ} \mathrm{C}$ 条 件下蔽光振荡培养, 振荡频率为 160 转 $/ \mathrm{min}$.

\section{2 分析方法}

根据蓝藻降解速率, 分别于实验开始后第 $0 、 12 、 24 、 48 、 96 、 168 \mathrm{~h}$ 固定时刻取样, 每个浓度每次随机取 3 个试验瓶作为重复. 取样后迅速测定溶解氧 ( DO) 、 $\mathrm{pH}$ 值及电导率; 每个试验瓶所有样品经 $0.45 \mu \mathrm{m}$ 醋酸纤 维滤膜抽滤, 取滤膜上蓝藻测叶绿素 a ( Chl. a) 浓度, 取滤液测溶解性污染物含量. 有机物指标用化学需氧量 $\left(\mathrm{COD}_{\mathrm{Cr}}\right)$ 和 $\mathrm{UV}_{254}$ 表征; 营养盐的释放用氮磷指示, 分别测定总溶解性氮 $(\mathrm{TDN})$ 、硝态氮 $\left(\mathrm{NO}_{3}^{-}-\mathrm{N}\right)$ 、亚硝态氮 $\left(\mathrm{NO}_{2}^{-}-\mathrm{N}\right)$ 、铵态氮 $\left(\mathrm{NH}_{4}^{+}-\mathrm{N}\right)$ 、总溶解性磷 ( TDP). 溶解性无机氮 (DIN) 以 $\mathrm{NO}_{3}^{-}-\mathrm{N} 、 \mathrm{NO}_{2}^{-}-\mathrm{N}^{-} \mathrm{NH}_{4}^{+}-\mathrm{N}$ 之和表示, 溶解性有机氮 (DON) 为总溶解性氮 ( TDN) 与 DIN 之差. 相关测定方法参照《水和废水监测分析方法 (第 四版) $\rangle^{[14]}$.

Chl. a 的降解速率采用 Olson 的指数衰减模型 ${ }^{[15]}$ 计算:

$$
C_{t} / C_{0}=\mathrm{e}^{-k t}
$$

式中, $C_{0}$ 为 Chl. a 的初始浓度 $(\mathrm{mg} / \mathrm{L}) ; C_{t}$ 为降解 $t$ 时间的 Chl. a 浓度 $(\mathrm{mg} / \mathrm{L}) ; t$ 为分解时间 $(\mathrm{d}) ; k$ 即为降解 速率常数 $\left(\mathrm{d}^{-1}\right)$.

Chl. a 在 $t$ 时间内的降解率 $r$ 计算公式为:

$$
r=\frac{C_{0}-C_{t}}{C_{0}} \times 100 \%
$$




\section{2 结果与分析}

\section{1 表观特征和 Chl. a 变化特征}

试验开始时各组试验瓶中藻类均呈绿色, 且漂浮于水体表层, 水体较清澈. $24 \mathrm{~h}$ 后, 蓝藻逐渐沉降到瓶 底. $D_{\mathrm{L}}$ 和 $\mathrm{D}_{\mathrm{M}}$ 组蓝藻逐渐变黄; $\mathrm{D}_{\mathrm{H}}$ 组试验瓶中蓝藻未明显变黄, 但藻液从 $48 \mathrm{~h}$ 开始逐渐变为蓝紫色. 3 组藻液 均散发出恶臭,并持续到实验结束.

蓝藻厌氧分解 $168 \mathrm{~h}, \mathrm{D}_{\mathrm{L}} 、 \mathrm{D}_{\mathrm{M}}$ 和 $\mathrm{D}_{\mathrm{H}}$ 组初始 Chl. a 含量分别从 $2.18 、 10.79 、 40.65 \mathrm{mg} / \mathrm{L}$ 降至 1.59、5.57、 $27.69 \mathrm{mg} / \mathrm{L}$, 降解率相应为 30\%、48\%、32\%（图 1a) ; 其中, $24 \mathrm{~h}$ 内降解率分别为 5\%、13\%、24\% . 根据 Olson 的指数衰减模型对 Chl. a 的降解速率进行拟合结果表明 (图 1b), 蓝藻密度不同的系统中 Chl. a 的降解速率 不同, $\mathrm{D}_{\mathrm{L}} 、 \mathrm{D}_{\mathrm{M}}$ 和 $\mathrm{D}_{\mathrm{H}}$ 降解速率常数分别为 $0.074 、 0.133$ 和 $0.081 \mathrm{~d}^{-1}$.
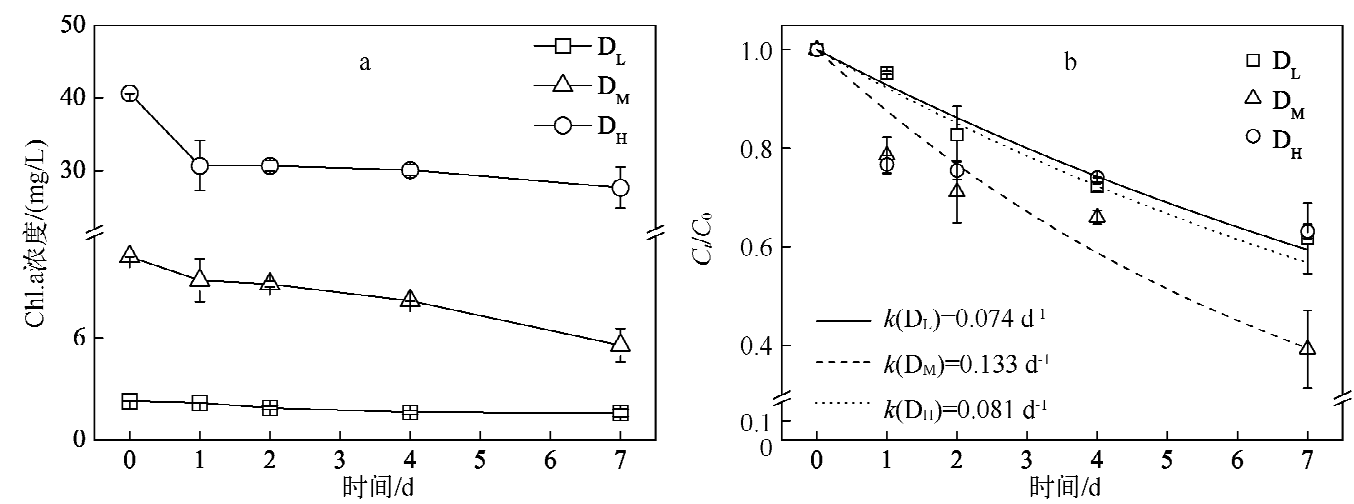

图 1 蓝藻厌氧分解过程中 Chl. a 浓度变化 (a) 和降解速率 $(\mathrm{b})$

Fig. 1 Variations(a) and degradation rates(b) of Chl. a concentration during the anaerobic decomposition of cyanobacteria

\section{2. $2 \mathrm{DO}, \mathrm{pH}$ 和电导率的变化特征}

$\mathrm{D}_{\mathrm{L}} 、 \mathrm{D}_{\mathrm{M}}$ 和 $\mathrm{D}_{\mathrm{H}}$ 组藻液在 $12 \mathrm{~h}$ 内 $\mathrm{DO}$ 分别从 $6.76 、 8.04 、 7.05 \mathrm{mg} / \mathrm{L}$ 降至 $0.50 \mathrm{mg} / \mathrm{L}$ 以下, 经过短暂的好氧 降解过程后, 进人厌氧降解阶段.

由于蓝藻细胞内有机质含量较高, 厌氧分解产生有机酸, 所以 3 组蓝藻藻液 $\mathrm{pH}$ 均呈酸性 (图 2a). 在实 验过程中, $\mathrm{pH}$ 先降低后升高. 这可能是因为实验前期生成大量有机酸使 $\mathrm{pH}$ 降低; 实验后期, 随着有机氮的 降解,产生 $\mathrm{NH}_{4}^{+}$而导致 $\mathrm{pH}$ 回升.

电导率反映水体中离子成分的含量情况,进而可反映湖泊富营养化发生的程度 ${ }^{[16]}$. 蓝藻堆积死亡分解 产生大量无机盐离子和有机酸, 导致电导率持续升高, 并且随蓝藻密度增大而增加 (图 $2 \mathrm{~b}$ ). 实验结束时, $\mathrm{D}_{\mathrm{L}} 、 \mathrm{D}_{\mathrm{M}}$ 和 $\mathrm{D}_{\mathrm{H}}$ 组电导率分别达到 $141 、 544$ 和 $949 \mu \mathrm{S} / \mathrm{cm}$.

\section{3 有机物的变化特征}

用化学需氧量 $\left(\mathrm{COD}_{\mathrm{Cr}}\right)$ 作为衡量蓝藻堆积死亡时产生溶解性有机物含量的指标, 数值越大说明水体受 污染越严重. $\mathrm{D}_{\mathrm{L}}$ 和 $\mathrm{D}_{\mathrm{M}}$ 藻液 $\mathrm{COD}_{\mathrm{Cr}}$ 浓度在升高过程中有短暂的下降, 继而继续升高; 而 $\mathrm{D}_{\mathrm{H}}$ 一直呈升高趋势 (图 3a). 试验结束时, $\mathrm{D}_{\mathrm{L}} 、 \mathrm{D}_{\mathrm{M}}$ 和 $\mathrm{D}_{\mathrm{H}}$ 组 $\mathrm{COD}_{\mathrm{Cr}}$ 分别达到 $40.75 、 70.78$ 和 $225.20 \mathrm{mg} / \mathrm{L}$, 表明蓝藻堆积死亡过程 中产生大量有机物, 且与蓝藻初始密度呈正比 $\left(R^{2}=0.997\right)$.

在厌氧条件下, 蓝藻可被微生物分解成分子结构复杂的腐殖质类物质, 大多为芳烃化合物和具有共轭 双键的有机化合物, 与 $U V_{254}$ 值正相关, 且分子量越大其 $U V_{254}$ 越高 ${ }^{[17]} . D_{L}$ 和 $D_{\mathrm{M}}$ 藻液 $U V_{254}$ 在第 $24 \mathrm{~h}$ 分别上 升至 0.13 和 $0.42 \mathrm{~cm}^{-1}$, 随后逐渐降低; $\mathrm{D}_{\mathrm{H}}$ 组 $\mathrm{UV}_{254}$ 在 $24 \mathrm{~h}$ 内迅速升高至 $2.43 \mathrm{~cm}^{-1}$ 后缓慢上升, $96 \mathrm{~h}$ 达到最 大值 $\left(3.25 \mathrm{~cm}^{-1}\right.$ ) 后又呈下降趋势 (图 $3 b$ ). 

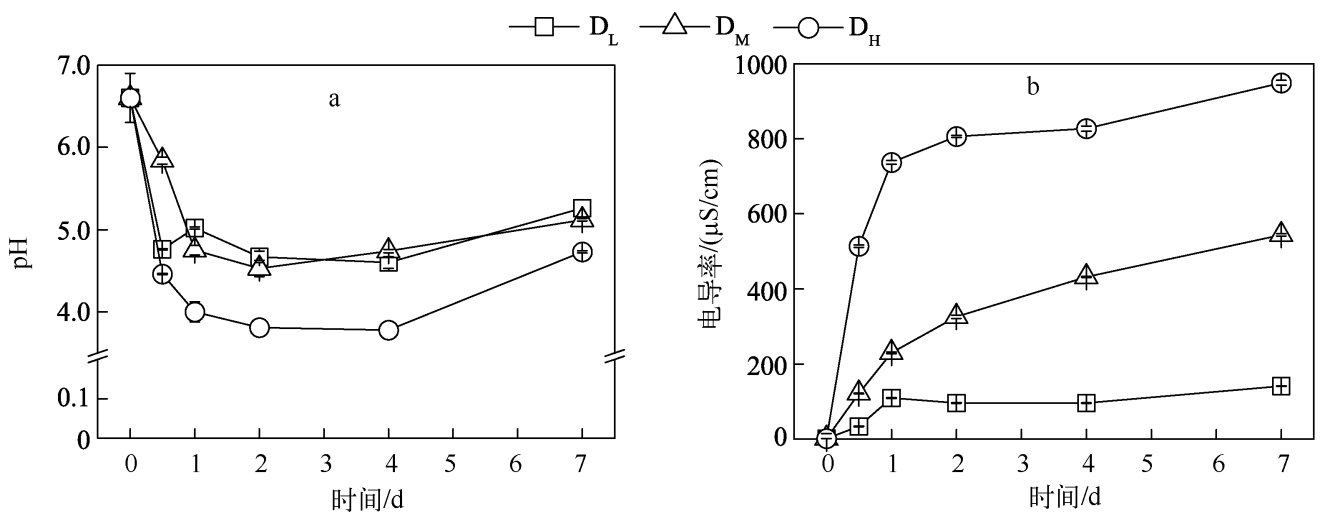

图 2 蓝藻厌氧分解过程中水体 $\mathrm{pH}$ ( a ) 和电导率 (b) 的变化

Fig. 2 Variations of $\mathrm{pH}$ (a) and conductivity (b) of the water during the anaerobic decomposition of cyanobacteria
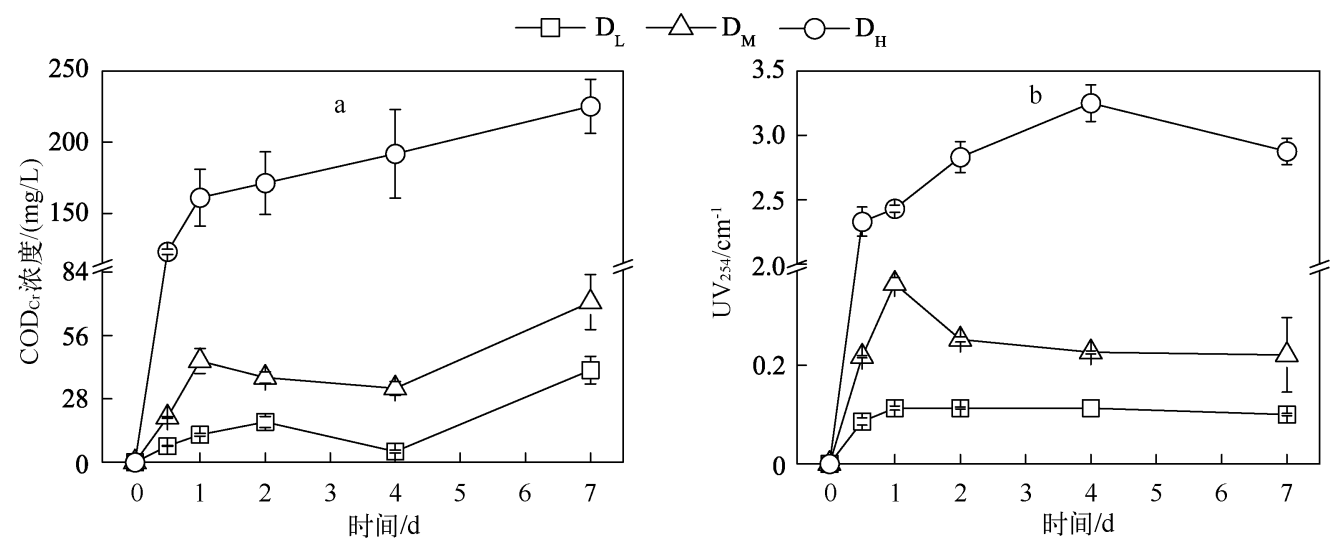

图 3 蓝藻厌氧分解过程中有机物浓度变化

Fig. 3 Variations of organic compounds concentrations of water during the anaerobic decomposition of cyanobacteria

\section{4 氮、磷的释放}

蓝藻分解释放各形态氮的浓度均随蓝藻堆积密度的增大而增加, 但趋势有所差别 (图 4). $\mathrm{D}_{\mathrm{L}}$ 组 TDN 浓 度在 $48 \mathrm{~h}$ 内上升至 $9.15 \mathrm{mg} / \mathrm{L}$, 而后减缓, 第 $96 \mathrm{~h}$ 后浓度继续上升, 实验结束时浓度为 $19.36 \mathrm{mg} / \mathrm{L} ; \mathrm{D}_{\mathrm{M}}$ 组 TDN 在第 $24 \mathrm{~h}$ 浓度即达到 $28.16 \mathrm{mg} / \mathrm{L}$, 占最终浓度的 $57 \%$, 随后缓慢升高; 而 $\mathrm{D}_{\mathrm{H}}$ 组第 $48 \mathrm{~h} \mathrm{TDN}$ 浓度升至 $104.86 \mathrm{mg} / \mathrm{L}$, 继而逐渐降低, 实验结束时浓度为 $81.03 \mathrm{mg} / \mathrm{L} . \mathrm{D}_{\mathrm{L}} 、 \mathrm{D}_{\mathrm{M}}$ 和 $\mathrm{D}_{\mathrm{H}}$ 组藻液 $\mathrm{DON}$ 分别在第 $48 、 24$ 、 $48 \mathrm{~h}$ 达到浓度峰值, 分别为 $6.68 、 20.09$ 和 $73.91 \mathrm{mg} / \mathrm{L}$, 随后分别下降至 $1.84 、 3.83 、 17.59 \mathrm{mg} / \mathrm{L}$. DIN 与 $\mathrm{NH}_{4}^{+}-\mathrm{N}$ 释放趋势一致, $\mathrm{D}_{\mathrm{L}}$ 组浓度升高后又有所下降, 继而继续上升; $\mathrm{D}_{\mathrm{M}}$ 组浓度持续上升; $\mathrm{D}_{\mathrm{H}}$ 组在第 $24 \mathrm{~h}$ 上 升至 $28.31 \mathrm{mg} / \mathrm{L}$, 占最终释放量的 $45 \% . \mathrm{D}_{\mathrm{L}} 、 \mathrm{D}_{\mathrm{M}}$ 和 $\mathrm{D}_{\mathrm{H}}$ 组 $\mathrm{NH}_{4}^{+}-\mathrm{N}$ 最终浓度分别为 17.52、44.06 和 $59.41 \mathrm{mg} / \mathrm{L}$, 均占相应 DIN 含量的 $90 \%$ 以上. $\mathrm{NO}_{3}^{-}-\mathrm{N}$ 浓度先升高后降低, 甚至减少为 $0 . \mathrm{NO}_{2}^{-}-\mathrm{N}$ 在整个过程 中含量均低于 $0.01 \mathrm{mg} / \mathrm{L}$, 可忽略不计.

TDP 的释放过程与 TDN 差异较大, TDP 释放浓度逐渐升高, $48 \mathrm{~h}$ 之后趋于平衡, $168 \mathrm{~h}$ 后 $\mathrm{D}_{\mathrm{L}} 、 \mathrm{D}_{\mathrm{M}}$ 和 $\mathrm{D}_{\mathrm{H}}$ 组浓度分别达到 $2.76 、 11.73$ 和 $44.47 \mathrm{mg} / \mathrm{L}$, 并与蓝藻初始密度呈正比 $\left(R^{2}=0.999\right)$.

\section{5 黑臭指数的变化}

蓝藻大规模聚集并堆积死亡, 导致溶解氧迅速降低, 铵态氮浓度升高, 水体呈黑色或酱褐色, 有明显臭 

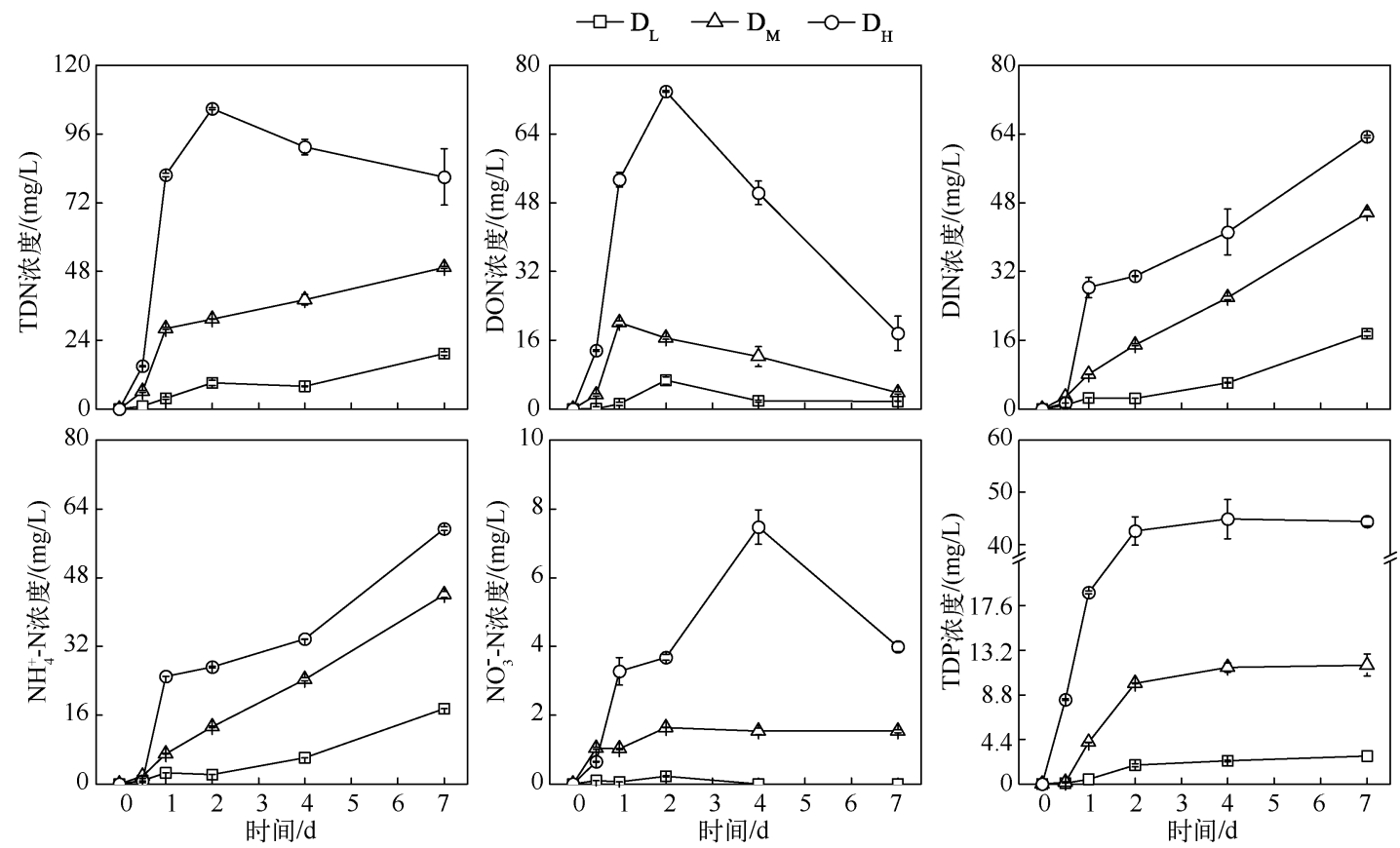

图 4 蓝藻厌氧分解过程中氮、磷浓度变化

Fig. 4 The variations of concentrations of nitrogen and phosphorus during the anaerobic decomposition of cyanobacteria

味 ${ }^{[8]}$. 蓝藻水华产生的黑臭现象可用黑臭指数 $I$ 表征, $I$ 与水中 $\mathrm{NH}_{4}^{+}-\mathrm{N}$ 浓度和 $\mathrm{DO}$ 饱和百分率之间的相互关 系为 ${ }^{[18]}$ :

$$
I=C /\left(\frac{D O}{D O_{0}}+0.4\right)
$$

式中, $I$ 为黑臭指数; $C$ 为 $\mathrm{NH}_{4}^{+}-\mathrm{N}$ 的浓度 $(\mathrm{mg} / \mathrm{L}) ; D O$ 为水体溶解氧浓度 $(\mathrm{mg} / \mathrm{L}) ; D O_{0}$ 为实测水温的饱和溶 解氧浓度 $(\mathrm{mg} / \mathrm{L})$.

当 $I>5$ 时, 表明水质发生异臭 ${ }^{[18]}$. 蓝藻堆积进人 厌氧分解过程, 溶解氧浓度为 $0 \mathrm{mg} / \mathrm{L}$, 则 $\mathrm{NH}_{4}^{+}-\mathrm{N}$ 含量 超过 $2 \mathrm{mg} / \mathrm{L}$ 即产生异臭. 在试验 $48 \mathrm{~h}$ 后, 3 组实验系统 $I>5$, 可见蓝藻堆积极易引发水体黑臭现象 (图 5).

\section{6 对水源地水质的影响}

为了探讨蓝藻厌氧堆积对水源地水质造成的影响, 本文尝试将厌氧分解模拟试验获得的污染物释放量应 用于巢湖东部水源区.假设蓝藻戻氧分解产生的可溶性 污染物全部垂直进人水柱中, 以每年 5-10 月蓝藻暴发 期间巢湖东部水源区平均水深 $1.5 \mathrm{~m}$ 和本试验所用碘 量瓶高度 $10 \mathrm{~cm}$ 进行换算, 获得蓝藻厌氧堆积释放至水 体中的污染物浓度 (图 6). 根据我国地表水环境质量标 准, 集中式生活饮用水地表水源地二级保护区需达到地 表水环境质量 III 类水标准 (GB/T 3838-2002) (其中 $\mathrm{TP}$ 浓度 $\leqslant 0.05 \mathrm{mg} / \mathrm{L}, \mathrm{TN}$ 浓度 $\leqslant 1.0 \mathrm{mg} / \mathrm{L}, \mathrm{NH}_{4}^{+}-\mathrm{N}$ 浓度 $\leqslant$

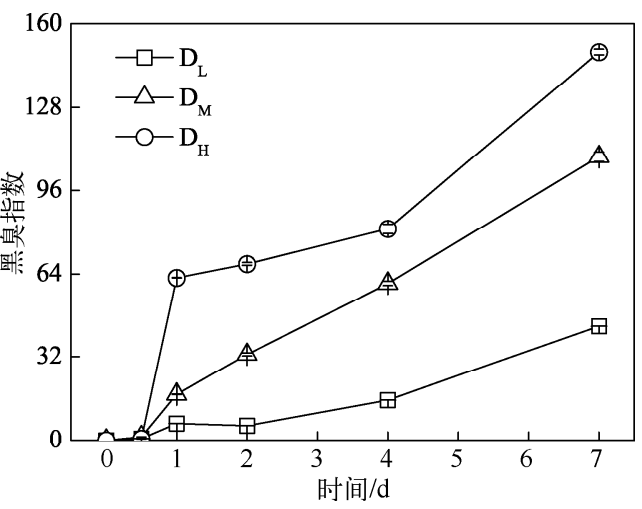

图 5 蓝藻厌氧分解过程中黑臭指数变化

Fig. 5 Changes of odour intensive indexes during the anaerobic decomposition of cyanobacteria 
$1.0 \mathrm{mg} / \mathrm{L}, \mathrm{COD}$ 浓度 $\leqslant 20 \mathrm{mg} / \mathrm{L})^{[19]}$. 不同密度蓝藻堆积分解造成水源区 $\mathrm{TP} 、 \mathrm{TN}$ 和 $\mathrm{NH}_{4}^{+}-\mathrm{N}$ 浓度均超过地表 III 类水质标准. 当蓝藻密度为 $2.23 \times 10^{12} \mathrm{cells} / \mathrm{L}$ 时, 水源区 $\mathrm{TP} 、 \mathrm{TN}$ 和 $\mathrm{NH}_{4}^{+}-\mathrm{N}$ 浓度将分别为 $0.18 、 1.29$ 、 $1.17 \mathrm{mg} / \mathrm{L}$; 蓝藻密度为 $1.19 \times 10^{13}$ cells $/ \mathrm{L}$ 时, TP、TN 和 $\mathrm{NH}_{4}^{+}-\mathrm{N}$ 浓度分别达到 $0.78 、 3.29$ 和 $2.93 \mathrm{mg} / \mathrm{L}$; 蓝藻 密度为 $4.47 \times 10^{13}$ cells $/ \mathrm{L}$ 时, TP、 TN 和 $\mathrm{NH}_{4}^{+}-\mathrm{N}$ 浓度分别达到 $2.96 、 5.40$ 和 $3.96 \mathrm{mg} / \mathrm{L}$, 这与巢湖水源区实 际监测值相近. 2010 年 7 月巢湖东部水源地蓝藻堆积密度为 $(3.20 \pm 0.53) \times 10^{12}$ cells $/ \mathrm{L}$ 时, TP、TN 和 $\mathrm{NH}_{4}^{+}-\mathrm{N}$ 浓度分别为 $0.63 \pm 0.18 、 8.31 \pm 4.45$ 和 $1.16 \pm 0.84 \mathrm{mg} / \mathrm{L}$. 但试验计算得到的 COD 释放量最大值为 $15.0 \mathrm{mg} / \mathrm{L}\left(\mathrm{D}_{\mathrm{H}}\right.$ 组, 第 $\left.168 \mathrm{~h}\right)$ 与实际监测值 $(225 \pm 110 \mathrm{mg} / \mathrm{L})$ 差别较大. 并且蓝藻厌氧分解对水源区的影响非 常迅速, 蓝藻堆积 $48 \mathrm{~h}$ 释放的氮磷就能造成水源区 $\mathrm{TP} 、 \mathrm{TN}$ 和 $\mathrm{NH}_{4}^{+}-\mathrm{N}$ 浓度超过标准限值, 如 $\mathrm{D}_{\mathrm{L}}$ 组 $\mathrm{TP}$ 为 $0.12 \mathrm{mg} / \mathrm{L}, \mathrm{D}_{\mathrm{M}}$ 组 $\mathrm{TN}$ 为 $2.10 \mathrm{mg} / \mathrm{L}, \mathrm{D}_{\mathrm{H}}$ 组 $\mathrm{NH}_{4}^{+}-\mathrm{N}$ 为 $1.82 \mathrm{mg} / \mathrm{L}$.

\section{3 讨论}

水华蓝藻在适当的温度、光照和风力条件下大量堆积, 导致水体中溶解氧大幅下降并趋于零, 使蓝藻在 厌氧条件下死亡分解, 并对湖泊水体产生影响. 蓝藻堆积密度不同, 厌氧分解过程有所变化. $24 \mathrm{~h}$ 内, Chl. a 降解率随蓝藻密度增加而增大, 说明堆积密度越大, 蓝藻死亡越迅速; 而 $168 \mathrm{~h}$ 内 $\mathrm{D}_{\mathrm{M}}$ 组 $\mathrm{Chl}$. a 表现出更快的 分解速率, 可能是因为该蓝藻密度更适宜分解细菌的生长, 细菌活性相对较高 ${ }^{[20]}$. 在自然衰亡过程中, 蓝藻 会释放藻蓝素, 颜色逐渐由绿色变为黄绿色, 再变为浅黄色, 最后变为白色残体; 周围水体可能会出现蓝紫 色 ${ }^{[21]}$. 本研究发现, 当蓝藻堆积密度 $<1.19 \times 10^{13} \mathrm{cell} / \mathrm{s} / \mathrm{L}\left(\mathrm{D}_{\mathrm{M}}\right)$ 时, 蓝藻颜色逐渐由绿色变为黄色, 蓝藻细胞 破裂释放的色素并未在水体中积累, 水体未明显变色. 而当蓝藻密度更高 (达到 $4.47 \times 10^{13} \mathrm{cells} / \mathrm{L}$ ) 时水体呈 蓝紫色, 可能是因为蓝藻细胞破裂释放出大量藻蓝素 ${ }^{[21]}$, 且其释放速率远高于降解速率. 第 $48 \mathrm{~h}$ 后 3 组试 验系统的黑臭指数均 $>5$, 水体异臭. 另外, 部分水华蓝藻可产生具有霉臭味的次生代谢产物如土臭素、二甲 基异茨醇等, 蓝藻衰亡时这些嗅味物质从细胞内大量释放至水体中, 进一步加剧湖泊异味问题 ${ }^{[22]}$. 可见, 高 密度蓝藻厌氧降解会影响湖泊感官性状.

蓝藻堆积死亡过程中, 水体中 $\mathrm{COD}_{\mathrm{Cr}}$ 持续升高, $\mathrm{UV}_{254}$ 呈先升高后降低趋势; 并且蓝藻密度越高, $\mathrm{UV}_{254}$ 表 征的芳香性有机物在水体中累积时间越长. 在蓝藻戻氧分解过程中, 先产生分子量较大的有机物, 随后逐渐 分解为小分子有机物. 这是由于厌氧分解可使蓝藻细胞内碳水化合物、蛋白质、脂肪等复杂的有机物质水解 和发酵转化为单糖、氨基酸、肽等, 并进一步分解成分子量更小的物质. 蓝藻戻氧分解释放的挥发性硫化物、 二甲基三硫等硫醚类物质与底泥中的重金属化合形成致黑物质在风浪作用下悬浮, 导致水体发黑, 会引发 “黑水团” 现象, 并伴有刺激性异味气体产生 ${ }^{[7-8]}$. 以往研究报导出现“黑水团” 的水域, 电导率达 $774 \mu \mathrm{S} / \mathrm{cm}$, 并且有机物和氮、磷, 尤其是 $\mathrm{NH}_{4}^{+}-\mathrm{N}$ 浓度急剧升高与蓝藻腐败分解密切相关 ${ }^{[8-10]}$. 这与本研究中高密度蓝藻 厌氧分解水体电导率达到 $949 \mu \mathrm{S} / \mathrm{cm}$ 的结果一致, 蓝藻厌氧分解释放大量有机酸和无机盐离子, 使水体电 导率大幅升高. 可见, 高密度蓝藻厌氧分解会改变水体的溶解氧、酸碱度、电导率等物理性质, 使水体中有机 物含量升高, 导致湖泊水环境恶化.

湖泊蓝藻水华发生后, 大量蓝藻细胞分解释放的氮磷是水体营养盐的一个重要来源. 本研究中高密度 蓝藻 $\left(4.47 \times 10^{13}\right.$ cells $\left./ \mathrm{L}\right)$ 厌氧培养 $168 \mathrm{~h}$ 后, 释放到水体中的 TDN 和 TDP 浓度分别达 $81.03 \mathrm{mg} / \mathrm{L}$ 和 $44.47 \mathrm{mg} / \mathrm{L}$, 并释放出大量 $\mathrm{NH}_{4}^{+}-\mathrm{N}$ (浓度为 $59.41 \mathrm{mg} / \mathrm{L}$ ). 蓝藻堆积死亡分解过程中, 细胞破裂释放出的大 量颗粒有机氮 (PON) 逐渐通过微生物活动转化为 DON, 并进一步分解为 DIN. 当水体中含有溶解氧时, 有机 氮在好氧微生物作用下分解产生 $\mathrm{NH}_{4}^{+}-\mathrm{N}$, 同时硝化细菌使一部分 $\mathrm{NH}_{4}^{+}-\mathrm{N}$ 经硝化作用转化为 $\mathrm{NO}_{3}^{-}-\mathrm{N}$. 随着 氧气的消耗, PON 在厌氧微生物作用下直接由氨化作用生成 $\mathrm{NH}_{4}^{+}-\mathrm{N}$ 或先生成 DON 后逐渐矿化为 $\mathrm{NH}_{4}^{+}-\mathrm{N}$, 另有部分 $\mathrm{NO}_{3}^{-}-\mathrm{N}$ 也可通过氨异化作用被还原成 $\mathrm{NH}_{4}^{+}-\mathrm{N}^{[23]}$. $\mathrm{NO}_{3}^{-}-\mathrm{N}$ 和 $\mathrm{NO}_{2}^{-}-\mathrm{N}$ 在反硝化作用或硝酸盐异化 还原作用的系列反应中被还原, 产生气态的 $\mathrm{N}_{2}$ 和 $\mathrm{N}_{2} \mathrm{O}$ 释放到大气中, 造成一定的 $\mathrm{N}$ 损耗 ${ }^{[24]}$, 从而使系统内 TDN 浓度呈先升高后略微降低趋势. $\mathrm{N}_{2} \mathrm{O}$ 是温室气体,但目前富营养化湖泊逸散的 $\mathrm{N}_{2} \mathrm{O}$ 气体尚无定量研究. 蓝藻分解速率远高于一般水生高等植物残体, 因此短期内可能会有更大比例的营养物质以溶解态营养盐的 形式留在水体中 ${ }^{[12]}$. 试验结果表明蓝藻堆积 $48 \mathrm{~h}$ 即造成水源区水质严重下降, $\mathrm{TP} 、 \mathrm{TN}$ 和 $\mathrm{NH}_{4}^{+}-\mathrm{N}$ 浓度高于 


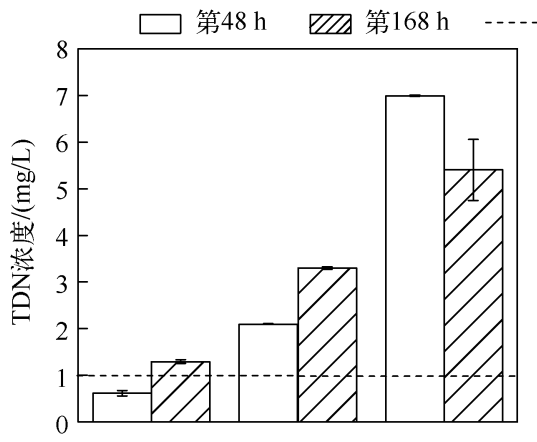

GB/T 3838-2002中 III 类水污染物浓度上限值
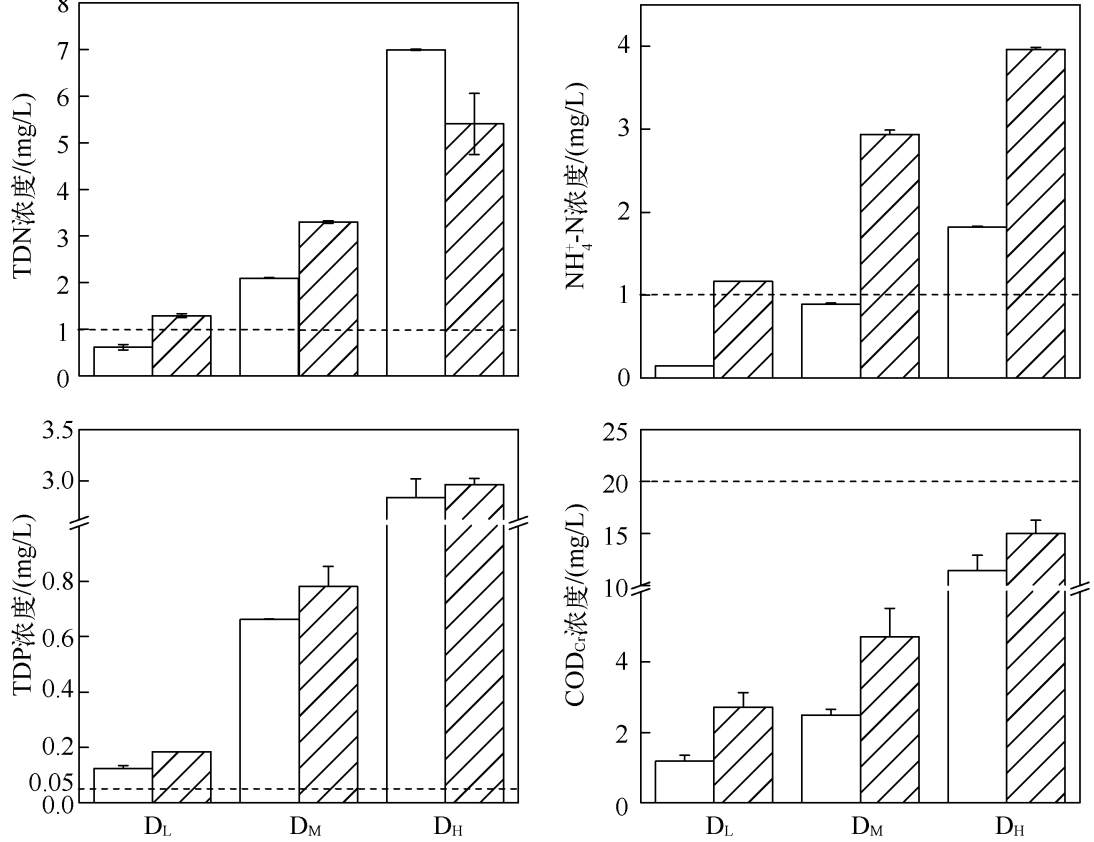

图 6 蓝藻厌氧分解释放至水源地水体中的污染物浓度变化

Fig. 6 Changes of contaminant concentrations during the anaerobic decomposition of cyanobacteria in source water

地表水环境质量 III类水标准限值 ( GB/T 3838-2002). 蓝藻厌氧分解过程水体中 $\mathrm{NH}_{4}^{+}-\mathrm{N}$ 含量占绝对优势, 可为藻类再生长提供营养条件, 从而引起蓝藻水华再次暴发. 而且水源区蓝藻堆积死亡, 导致进人自来水厂 的原水含氮量过高, 影响自来水出水质量. 尽管目前还没有关于饮用水中 $\mathrm{NH}_{4}^{+}-\mathrm{N}$ 危害人体健康的报道, 但 自来水中高浓度的 $\mathrm{NH}_{4}^{+}-\mathrm{N}$ 可通过硝化反应产生大量 $\mathrm{NO}_{3}^{-}-\mathrm{N}$,并与氯发生反应,使自来水消毒剂的用量大大 增加, 产生令人戻恶的嗅和味 ${ }^{[25]}$. 藻类及其降解产物在氯化消毒过程中还会产生有害健康消毒副产物 ${ }^{[26]}$. 近年来,含氮消毒副产物 (N-DBPs) 在饮用水中不断被检出,尽管含量远低于常规消毒副产物,但其危害却远 高于后者, 而水中 DON 化合物为 N-DBPs 主要前驱物 ${ }^{[27]}$. 因此, 高密度蓝藻堆积死亡产生的大量氮磷释放至 水体中,会加剧湖泊富营养化并危害饮用水安全.

湖泊富营养化和蓝藻水华现象的发生, 使得水源地的安全性下降, 甚至引起饮用水危机. 蓝藻大量堆积 死亡时, 污染物的释放量随堆积时间而变化,在 $48 \mathrm{~h}$ 即对湖泊水源地水质安全形成威胁. 因此, 及时打捞水 华蓝藻并防止其堆积死亡, 可有效抑制蓝藻水华危机的发生.

\section{4 结论}

高密度蓝藻堆积导致水体的溶解氧迅速下降, $12 \mathrm{~h}$ 内进人厌氧状态; 蓝藻在厌氧条件下腐烂分解并散 发出恶臭, 使湖泊水体感官性状下降. 高密度蓝藻厌氧分解过程中水体 $\mathrm{pH}$ 呈酸性, 电导率逐渐升高, 并释放 大量有机物和可溶性营养盐至水体中,甚至导致湖泊水体中 $\mathrm{TN} 、 \mathrm{TP}$ 和 $\mathrm{NH}_{4}^{+}-\mathrm{N}$ 浓度超过地表水环境质量标 准 GB/T 3838-2002 中类水标准的限值. 随着蓝藻堆积密度的升高, 污染物释放强度大大增加, 对水环境 的影响也越大. 为避免蓝藻大量堆积死亡致水源区水质下降并影响自来水出水质量,建议在水华期间及时 打捞蓝藻.

\section{5 参考文献}

[ 1 ] Deng DG, Xie P, Zhou Q et al. Studies on temporal and spatial variations of phytoplankton in Lake Chaohu. Journal of 
Integrative Plant Biology, 2007, 49(4): 409-418.

[ 2 ] Zhang XJ, Chen C, Ding JQ et al. The 2007 water crisis in Wuxi, China: Analysis of the origin. Journal of Hazardous Materials, 2010, 182(1/2/3): 130-135.

[ 3] 倪兆奎,王圣瑞, 金相灿等. 云贵高原典型湖泊富营养化演变过程及特征研究. 环境科学学报, 2011,31 (12): 2681-2689.

[ 4 ] 秦伯强. 长江中下游浅水湖泊富营养化发生机制与控制途径初探. 湖泊科学,2002,14(3):193-202.

[ 5 ] 陈开宁,李文朝, 吴庆龙等. 滇池蓝藻对沉水植物生长的影响. 湖泊科学, 2003,15(4) :364-368.

[ 6 ] 朱梦圆,朱广伟,王永平.太湖蓝藻水华衰亡对沉积物氮、磷释放的影响. 环境科学,2011,32(2):409-415.

[ 7 ] 刘国锋,何 俊,范成新等. 藻源性黑水团环境效应: 对水-沉积物界面处 Fe、Mn、S 循环影响. 环境科学,2010,31 (11) :2652-2660.

[ 8 ] 盛 东,徐兆安,高 怡. 太湖湖区“黑水团”成因及危害分析. 水资源保护,2010,26(3):41-44.

[ 9 ] 孔繁翔,马荣华,高俊峰等. 太湖蓝藻水华的预防、预测和预警的理论与实践. 湖泊科学, 2009,21(3):314-328.

[10］秦伯强, 王小冬, 汤祥明等. 太湖富营养化与蓝藻水华引起的饮用水危机一一原因与对策. 地球科学进展, 2007,22 (9) :896-906.

[11] 陈伟民, 蔡后建. 微生物对太湖微囊藻的好氧降解研究. 湖泊科学, 1996,8(3):248-252.

[12] 李 柯,关保华,刘正文. 蓝藻碎屑分解速率及氮磷释放形态的实验分析. 湖泊科学,2011,23(6):919-925.

[13] Chuai XM, Ding W, Chen XF et al. Phosphorus release from cyanobacterial blooms in Meiliang Bay of Lake Taihu, China. Ecological Engineering, 2011, 37(6): 842-849.

[14] 国家环境保护总局. 水和废水监测分析方法:第 4 版. 北京: 中国环境科学出版社,2002:200-284.

[15] Olson JS. Energy storage and the balance of producers and decomposers in ecological systems. Ecology, 1963, 44(2): 322-331.

[16] 胡胜华, 叶艳婷, 贺 锋等. 武汉月湖近代沉积物中的硅藻组合与环境关系研究. 生态环境学报, 2011, 20(3): 490-498.

[17] 蒋绍阶,刘宗源. $U V_{254}$ 作为水处理中有机物控制指标的意义. 重庆建筑大学学报,2002,24(2):61-65.

[18］肖志成.氮在水环境中的影响及处理工艺. 环境污染与防治, $1988,3: 41-45$.

[19］ GB/T 3838-2002. 中华人民共和国国家标准地表水环境质量标准. 北京: 中国环境科学出版社,2002.

[20] Wang YY, Chen FZ. Decomposition and phosphorus release from four different size fractions of Microcystis spp. taken from Lake Taihu, China. Journal of Environmental Sciences, 2008, 20(7) : 891-896.

[21] 孟泽婧, 李玉成, 吴 涓等. 巢湖蓝藻衰亡过程中颜色及形态变化的室内模拟研究. 安徽农业科学, 2011,39(17): 10348-10352.

[22] Smith JL, GL Boyer, PV Zimba. A review of cyanobacterial odorous and bioactive metabolites: impacts and management alternatives in aquaculture. Aquaculture, 2008, 280 : 5-20.

[23] Downes MT. Aquatic nitrogen transformations at low oxygen concentrations. Appl Environ Microbiol, 1988, 54: 172-175.

[24] Kalff J. Limnology-Inland Water Ecosystems. New Jersey: Prentice-Hall, 2002: 274.

[25] 张成云,孙 莉,金立坚等. 生活饮用水中的铵态氮污染问题探讨. 中华医学研究杂志,2007,7 (6):495-498.

[26] Huang J, Graham N, Templeton M et al. A comparison of the role of two blue-green algae in thm and haa formation. Water Research, 2009, 43(12) : 3009-3018.

[27] Westerhoff P, Mash H. Dissolved organic nitrogen in drinking water supplies: a review. Aqua, 2002, 51 : 415-448. 